\title{
Del fracaso del desarrollo al desarrollo endógeno sustentable: La nueva Organización de Desarrollo Regional
}

\author{
Contreras, José J.* \\ Ochoa Arias, Alejandro** \\ Pilonieta Blanco, Claudia***
}

\section{Resumen}

El objetivo del presente artículo es colaborar en el debate en torno al fracaso del paradigma tecno-económico del desarrollo en Venezuela y sus implicaciones en la organización de Desarrollo Regional. En este orden de ideas el artículo presenta un breve esbozo del paradigma tecno-económico del desarrollo y del fracaso de su implantación en Venezuela. El fracaso se entenderá en términos de una catástrofe cultural en Venezuela que alcanza su crisis a finales del siglo XX. Como contraposición, se avanza una noción alternativa de desarrollo fundamentada en la promoción de la endogeneidady la sustentabilidad como nociones primordiales del despliegue de significados que buscan crear y re-crear la cultura local con sentido en lo nacional y lo universal y que se despliega a la luz de la Constitución de la República Bolivariana de Venezuela.

Palabras clave: Desarrollo, desarrollo endógeno, organización de desarrollo regional, educación, democracia participativa, valores de la sociedad venezolana.

\section{Recibido: 07-02-06. Aceptado: 11-12-06}

Miembro Visitante del Centro de Investigaciones en Sistemología Interpretativa de la Universidad de Los Andes-Mérida, Venezuela. E-mail: joaquin@ula.ve

** Profesor Titular. Centro de Investigaciones en Sistemología Interpretativa. Universidad de Los Andes-Mérida, Venezuela. E-mail: aleochoa@ula.ve

*** Profesora del Movimiento de Educación Popular Integral y Promoción Social "Fe y Alegría". Unidad Educativa Timoteo Aguirre Pe. El Valle - Mérida, Venezuela.

E-mail: pclaudia36@hotmail.com 


\section{The Failure of Development and Sustainable Endogenous Development: A New Organization for Regional Development}

\section{Abstract}

The purpose of this paper is to contribute to an ongoing debate over the failure of the technoeconomic development paradigm in Venezuela and its implications in Regional Development organizations. The article begins with a brief outline of the techno-economic paradigm of development and the failure of its implementation in Venezuela. The failure is understood as a cultural catastrophe in Venezuela which reached its crisis at the end of the twentieth century. As a contrasting possibility, an alternative notion of development, based on the promotion of endogenous concepts and sustainability as primary notions upon which to create and recreate local culture with a national and universal sense and that can be developed under the Constitution of the Venezuelan Bolivarian constitution.

Key words: Development, endogenous development, regional development organization, education, participative democracy, values in Venezuelan society.

\section{Introducción}

El objetivo del presente artículo es preguntar en torno al discurso del Desarrollo y su viabilidad institucional en una Organización de Desarrollo Regional (ODR). Al hacerlo, se despliega un proceso de búsqueda del sentido de la ODR en el marco histórico de la Venezuela del presente. Sin embargo, se requiere además explorar lo que conceptualmente se puede entender como el proceso histórico de construcción del concepto de desarrollo en la sociedad venezolana. Comencemos.

Entendemos como Organización de Desarrollo Regional (ODR) aquella cuyo objetivo es la promoción del desarrollo de una región particular de la República. Por ello la ODR debe planificar el desarrollo de la región desde sus potencialidades y en conjunción tanto con los planes de desarrollo de otras regiones como con el plan de desarrollo nacional.
Las ODR vienen funcionando en $\mathrm{Ve}$ nezuela desde la década de los sesenta como forma institucional de promoción del desarrollo del país. Su orientación formal ha sido dirigida hacia el desarrollo económico de la región en conformidad con el discurso político desarrollista propio de la segunda mitad del Siglo XX. Las ODR han servido como institución de implantación y seguimiento a nivel regional de las políticas de desarrollo económico dictadas por el gobierno nacional. No es de extrañar que en la década de los ochenta, cuando el discurso de la descentralización impregnó la institucionalidad venezolana, las ODR se convirtieran en organizaciones cada vez más impertinentes, sobreviviendo sólo por la inercia de otra época.

Es singular el modo como los ODR fueron paulatinamente perdiendo su vigencia porque ello revela la distancia entre la demanda de instituciones y la oferta de las mismas en el entramado social ve- 
nezolano. La elección directa de gobernadores y alcaldes, así como de los cuerpos deliberantes en las instancias estatales y municipales, debió propiciar una reestructuración en el modo de asumir el proceso de planificación y estímulo del desarrollo por parte del Estado venezolano. El que hayan quedado instituciones de planificación del poder central sin clara orientación en las regiones, revela hasta donde el proceso de descentralización no respondía a demandas auténticas de autonomía y acercamiento del gobierno a sus ciudadanos. Privaron, quizás, aspectos más vinculados a un "adelgazamiento" del Estado que perdió toda posibilidad de coordinación y articulación de políticas en un entramado de instituciones que ganaba en complejidad y que debiera además ganar en eficiencia y desempeño vinculado a los ciudadanos.

Las ODR se convirtieron así en mecanismos de supervisión y control central sin la capacidad política para articular proyectos y políticas de desarrollo que hicieran precisamente de las actividades de seguimiento y control el punto de partida para una interacción entre los actores locales y nacionales. La tarea se trastocó entonces en hacer un seguimiento tímido e inexacto de lo que acaecía en la región sin poder claramente establecer mecanismos de evaluación del desempeño institucional. Se puede concluir que fue un proceso de reducción de la presencia del estado a través de un proceso de descentralización fragmentado que dio lugar al surgimiento de "islas institucionales" que perdieron toda posibilidad de legitimarse en función de su desempeño por el bienestar del colectivo.
Hoy, en los primeros años del Siglo $X X I$, las ODR han regresado como tema de discusión del discurso político. Sin embargo, su pertinencia no aparece con la claridad suficiente. La poca claridad responde no tanto a una necesidad de revisar los procesos de articulación entre las ODR, el gobierno central y los gobiernos estadales y municipales sino, más bien, al desvanecimiento progresivo del significado del discurso del desarrollo. En tales circunstancias, las ODR pareciesen quedar sin un piso firme que le brinden pertinencia. Ahora bien, de ser este el caso, ¿Cómo es posible que la discusión política sobre la pertinencia de las ODR aparezca? ¿Qué nuevo sentido pudiesen jugar las ODR en las circunstancias históricas y culturales de la Venezuela de principios del Siglo XXI? ¿Tiene sentido la ODR en la actualidad?

Intentaremos acercarnos a algunas posibles respuestas a tales preguntas con el propósito de identificar caminos de reflexión que nos puedan acercar a otear el devenir histórico que subyace a la problemática actual. Para ello comenzaremos por presentar un muy breve recuento del devenir del discurso del desarrollo y su aplicación y resultados en Venezuela. Este recuento nos servirá de base para entender los cambios socio-políticos y culturales de la Venezuela del presente. Finalmente adelantaremos una interpretación del sentido de la ODR en nuestra actualidad.

\section{Breve acercamiento al discurso del desarrollo en Venezuela}

Desde hace más de medio siglo los países del mundo se han dividido en de- 
sarrollados y subdesarrollados o, más eufemísticamente, países desarrollados y países "en vías de desarrollo". El concepto de desarrollo si bien ha sido cambiante y difuso pareciese que se refiere a un proceso de evolución progresiva de la población de un país para alcanzar los niveles de las mayorías de los países llamados desarrollados a través de una economía basada en la producción industrial. A esas mayorías usualmente se les ha catalogado como la "clase media", sin mencionar con precisión cómo se califica en tal categoría.

Nótese que el desarrollo parece presentarse de este modo como un concepto tautológico. El desarrollo amerita del desarrollo para su definición. En efecto, esta recursividad apunta hacia una de sus características fundamentales. El desarrollo no fue ni es un concepto establecido a priori y que permitió dividir posteriormente a los países de acuerdo a ciertos estándares. Por el contrario, el desarrollo surgió como concepto posterior para validar que ciertos países, que ya se consideraban avanzados, eran más desarrollados y que el resto eran subalternos a ellos, subdesarrollados. Es decir, el desarrollo surgió como un modo de deslindar a los países no desarrollados de los que eran, de antemano, desarrollados.

Esta noción de desarrollo es dominada por una concepción tecno-económica que procura la industrialización. La industrialización es asumida como un fin en sí mismo que permitió la definición de indicadores de desarrollo que pretenden "medir" la prosperidad de los países, regiones y localidades a partir de criterios homogéneos que dividen al mundo en función de la industrialización alcanzada (Fuenmayor, 2000).

Los modos de alcanzar el desarrollo son múltiples pero el fin es el mismo, y debe ser el mismo, para todas las naciones del globo terráqueo. Dentro de estas múltiples variantes apareció un concepto derivado del desarrollo que es el llamado desarrollo local. Como tal se entiende la realización de las potencialidades de una localidad, medidas en términos de oportunidades de negocio y de desarrollo tecnológico industrial. Se trata así de crear condiciones que posibiliten el surgimiento y la competitividad de una red empresarial que permita el crecimiento económico de la zona. Para ello normalmente se escoge algún ramo de la industria con potencial en la región y se brindan una serie de estímulos para la creación de nuevas empresas en el área o para la atracción de las mismas. Asimismo, se procura brindar estímulos para la creación y atracción de una red de proveedores de productos y servicios que puedan ayudar en el sostenimiento de la dinámica empresarial. En algunos casos, también es posible que el mismo Estado cree empresas públicas en la localidad (Cárdenas, 2002).

Sin embargo, el industrialismo enfrentó diversos problemas para su realización. Uno de los más contundentes es la imposibilidad de la industrialización de todos los países del mundo. Tal como se argumenta en el informe presentado en 1973 por el Club de Roma, intitulado "Los Límites del Crecimiento", de seguir las tendencias de utilización de recursos y contaminación del medio ambiente generadas por el industrialismo, el planeta alcanzaría los límites de su crecimiento en el curso de cien años (Meadows, 1975). 
El desarrollo industrial al ser finito y potencialmente amenazante de la propia existencia de la vida en el planeta dio lugar a acciones políticas que han procurado revertir la tendencia industrialista sin dejar, necesariamente, de propiciar el desarrollo.

Es así como el desarrollo necesitó su reformulación sobre otras bases para superar este camino sin salida. En este sentido, en 1987 las Naciones Unidas publican el informe "Nuestro Futuro Común", mejor conocido como el "Informe Brundtland", en el cual se establece la prioridad por la búsqueda de un desarrollo sostenible que "satisfaga las necesidades del presente sin comprometer las posibilidades de que las futuras generaciones satisfagan las suyas propias" (World Commission on Environment and Development, 1987). Es en este orden de ideas que en la actualidad no puede hablarse de desarrollo sin que se busque simultáneamente el modo de atenuar sus efectos colaterales y sin experimentar cierta cautela sobre los riesgos asociados. Hoy día sólo se puede mencionar el desarrollo si procura ser sostenible y sustentable. Se trata de descentralizar el desarrollo con respecto a lo económico y formularlo pensando en el hombre como centro, como sujeto, y no como objeto del mismo. Visto así, podría plantearse que el desarrollo dejó de ser respuesta para convertirse en una interrogante para la sociedad, en la medida en que debe ajustarse a ella, y no al contrario, como ha ocurrido de manera recurrente en la historia.

Ahora bien, cabría preguntarse cómo se implantó este discurso en el caso venezolano y qué resultados ha generado.
El discurso del desarrollo entra en Venezuela con toda fuerza a partir de la segunda mitad del siglo XX. Como tal se promovió la industrialización y, en este mismo sentido, nos definimos como país subdesarrollado que debía, en consecuencia, desarrollarse.

Las políticas de promoción de la industrialización han sido diversas. Una de las más emblemáticas fue la Política de Sustitución de Importaciones (PSI). La PSI procuraba, gradualmente, sustituir las importaciones con producción nacional. Dado que el tejido empresarial era casi inexistente en la primera mitad del siglo XX, la sustitución de importaciones promovió la creación y protección de las empresas nacionales durante sus primeros años de implantación y crecimiento.

La promoción de la producción nacional se llevó a cabo, grosso modo, de la siguiente manera. Por una parte, se realizó la implantación en tierras venezolanas de plantas industriales diseñadas tomando en cuenta las condiciones propias de los países en Europa y los EE.UU. El Estado jugó un papel fundamental como propietario o como mecanismo financiero para facilitar la adquisición de industrias. Por otra parte, en lo relativo a la protección de las empresas, se procuró cerrar el mercado nacional a algunos productos extranjeros procurando así escudar a las empresas locales de tal suerte que pudiesen desarrollarse suficientemente para luego poder competir con los productos de otras partes del mundo.

El financiamiento de estos grandes proyectos de industrialización de la nación se llevó a cabo gracias al ingreso petrolero. En Venezuela, el petróleo, al igual que todos los demás recursos mineros, 
es propiedad del Estado y por lo tanto es un bien público. Es así como el Estado comenzó a utilizar los beneficios provenientes de la riqueza petrolera en la modernización de la nación, es decir, en su desarrollo como sociedad industrial.

Ahora bien, luego de medio siglo podemos aseverar que este proyecto de desarrollo en Venezuela fracasó tal y como lo revelan los diferentes indicadores de desempeño industrial y los bajos niveles de calidad de vida de los habitantes. En su lugar, se ha consolidado una economía rentística fundada en la industria petrolera y que ha permitido a través de una serie de mecanismos, tanto legales como ilegales, la acumulación de la renta petrolera en muy pocas manos. Dado que el petróleo en Venezuela es un bien del Estado por disposición de las leyes, y que éste constituye la riqueza fundamental de la sociedad, nos encontramos con que la nación ha sido enajenada de su riqueza. Es decir, la inmensa mayoría de la población ha sido despojada de su justo acceso a los beneficios provenientes del bien público material fundamental: el petróleo (Fuenmayor, 2001), (López Garay, 1991), (Baptista, 1997). Un caso concreto de cómo se llevaba a cabo la enajenación del bien público en la empresa estatal Petróleos de Venezuela S.A. puede verse en (Mommer, 2003).

En efecto, la economía venezolana -en apariencia y discurso considerada capitalista- revela en su interior una estructura inconsistente con la de la libre competencia y la producción industrial. En general, el desempeño empresarial venezolano muestra un proceso continuo de des-inversión y de reducción del salario real de los trabajadores en conjunción con un continuo incremento de los beneficios de los dueños de las empresas. Se trata así de una empresa tanto privada como pública que no logra el sostenido beneficio de sus accionistas a través de un incremento de su competitividad y su participación en el mercado, sino que lo logra a través de la reducción del salario de los trabajadores, de la reducción en la inversión en el mantenimiento y crecimiento de la empresa y de los contratos con el Estado que generan jugosos beneficios a través de una compleja red clientelista (Baptista, 1997).

Paralelamente ha habido un continuo e indiscriminado proceso de importación de bienes de consumo que ha transferido la riqueza nacional generada por la producción y comercialización del petróleo hacia los países desarrollados con la consecuente dependencia que esto genera. De este modo se entiende porqué parte importante de los empresarios nacionales se dedican principalmente al negocio de la importación y comercialización de bienes de consumo extranjeros. Dado lo anterior, es evidente que no se ha logrado generar redes estables de producción nacional, sino por el contrario, redes de comercialización altamente vulnerables a los vaivenes del entorno nacional e internacional.

En resumen, el proyecto desarrollista venezolano ha sido un fracaso ya que en vez de lograr construir una economía capitalista dinámica y competitiva ha creado una economía parasitaria que vive de contratos indebidos con el Estado en la que el necesario equilibrio de la sociedad capitalista entre el Estado (Io político) y la sociedad civil (lo económico) no existe (Baptista, 2004). Como resultado 
de esto, las riquezas provenientes del bien público petrolero se han dirigido hacia muy pocos beneficiarios. Por ejemplo, algunos cálculos indican que para principios de los años noventa el cincuenta por ciento del ingreso petrolero era absorbido sólo por el uno por ciento de la población, mientras que el ochenta por ciento de las familias venezolanas tenían ingresos inferiores al mínimo necesario para satisfacer sus necesidades alimenticias básicas (Fuenmayor y López Garay, 1991).

De este modo nos encontramos con que el fracaso del proyecto desarrollista es doble. No sólo no se logró crear la economía capitalista industrial competitiva que se buscaba, sino que tampoco se logró crear un nivel de bienestar aceptable para la mayoría de la población, condición básica para la dinámica capitalista industrial.

El proceso empeoró a partir de la década de los ochenta y especialmente en los noventa. El discurso del desarrollo transmutó en el discurso de la globalización y como tal se entendía el dominio al nivel mundial de las ideas del neoliberalismo. Bajo esta doctrina político-económica los países pasaron a concebirse única y exclusivamente como mercados. Los Estados fueron vistos como organizaciones cuya función se basaba en el sostenimiento y mantenimiento del espacio común que permite el intercambio entre individuos y organizaciones. De lo anterior, se entiende que dejó de tener sentido la protección de los mercados nacionales y se abrieron las fronteras al mercado global. De este modo, en el transcurso de unos pocos años, el mercado nacional se abrió a una competencia internacional que, encontrando en Venezuela una red empresarial no competitiva, arrasó y destruyó a la mayoría de las empresas, especialmente las manufactureras.

Es en estas condiciones que arriba Venezuela al siglo XXI. El proyecto modernizador ha fracasado. Sin embargo, no se trató exclusivamente de un fracaso como consecuencia de no haber logrado los objetivos planteados debido a errores de táctica, estrategia y/o cálculo. Se trata de un fracaso más profundo que afecta las entrañas de la nación venezolana.

\section{El fracaso cultural del proyecto modernizador venezolano}

Como ya lo hemos indicado el fracaso del proyecto del desarrollo se evidencia en los bajos niveles de calidad de vida de la población, en los exiguos indicadores de desempeño industrial y en la carencia de una economía capitalista suficientemente dinámica. Ahora bien, si recordamos que el desarrollo es un concepto tautológico que acude a sí mismo para definirse y que justifica de antemano la selección de aquellos países que son o no son desarrollados, puede entenderse que alcanzar el desarrollo sea considerado como llegar a ser igual a los países ya considerados desarrollados. Es decir, se entiende que el desarrollo sea un discurso que justifica el mimetismo por parte de los países subdesarrollados para convertirse en copias de los países desarrollados.

Llegar a ser desarrollado significa básicamente llegar a ser como los europeos. A mediados de los años cincuenta del siglo XX, este ideal era mejor representado por los Estados Unidos de América (EE.UU.), país en el que se había lo- 
grado materializar parte importante de los ideales de los colonizadores europeos que fundaron Nueva Inglaterra. De este modo el discurso del desarrollo se entendió como el trasplante de maquinarias, organizaciones y modelos creados en Europa y los EE.UU. y su implantación en nuestras latitudes con la esperanza de convertirnos en un país avanzado.

Ahora bien, el desarrollo industrial requiere de altas concentraciones de capital y mano de obra que permitan reforzar el mercado y asegurar una mano de obra barata. En consecuencia, el proyecto de desarrollo del país promovió y potenció un proceso de acelerada migración de la población campesina a las ciudades en procura de alcanzar los beneficios que resultaban del trabajo asalariado.

Pero el atractivo urbano no se limitaba únicamente a las oportunidades de trabajo asalariado, la ciudad industrial presentaba atractivos tecnológicos y de mercado que lucían placenteros para el hombre del siglo XX. La posibilidad de acceder a dispositivos tecnológicos como automóviles, teléfonos, televisores, reproductores de sonido o computadores o la posibilidad de ir a centros comerciales, vivir entre edificios de apariencia similar a los de Europa o contar con energía eléctrica era más factible desde la ciudad que desde las comunidades rurales. Por ello, la mayoría de los jóvenes nacidos durante el siglo XX en comunidades rurales migraron a las ciudades en procura de acceder a tales beneficios. El habitante de la ciudad era considerado como más desarrollado, más civilizado, que el del campo que era visto como más cercano a la barbarie, más subdesarrollado.
La migración masiva del campo a la ciudad permitió que en un período menor a los ochenta años la población del país pasara a ser de mayoritariamente campesina a mayoritariamente urbana. Este proceso desarraigó la cultura campesina sin lograr que se generara una cultura urbana fundada en el éxito del desarrollo industrial (Clarac, 1976; Fuenmayor, 2001). Por el contrario, lo que se acendró fue la actitud de mimetismo para llegar a "ser" como los europeos. Por ello, el indiscriminado consumo de bienes importados y el fracaso en la creación de una fuerte red empresarial nacional, se vieron acompañados de una orfandad cultural que espera únicamente copiar, actualizarse y consumir las creaciones de las culturas desarrolladas (Fuenmayor, 2001).

El fracaso del proyecto de nación del siglo XX dejó como herencia un conjunto de instituciones públicas que, siendo copias de sus contrapartes europeas y norteamericanas, no cumplieron con los objetivos formalmente establecidos. Se institucionalizó un Estado moderno en una sociedad no moderna. De allí, el incumplimiento e impertinencia del Estado $y$, en consecuencia, su utilización como mecanismo de enajenación de los bienes públicos por parte de las minorías dominantes. Ello posibilitó que a finales del siglo XX la institucionalidad apareciera como profundamente fragmentada. Por ello podría interpretarse que el Estado venezolano de finales del siglo XX dejó de ser la encarnación institucional de lo público para pasar a ser una fachada de modernidad y democracia que oculta el despojo de los bienes públicos por parte de redes clientelares. 
Dado todo lo anterior puede verse ahora que la enajenación que ha vivido el pueblo venezolano no ha sido única y exclusivamente la del petróleo como bien público sino que también le ha sido expropiada la posibilidad de lo público, de lo común, es decir, de su cultura. El fracaso cultural del proyecto modernizador llegó al punto cúspide en el momento en que se debilita toda posibilidad de cultura, de espacio público, de conformación de un nosotros, de un pueblo... de Venezuela. Este punto se logró al galope de la globalización del mercado como punta de lanza de la modernización tardía.

Con la globalización, las naciones se convierten única y exclusivamente en mercados. La cultura se reduce a objetos folclóricos de compra y venta (Contreras y Ochoa, 2000). Aunque para ser más acertados habría que decir que la globalización homogeneiza el mundo alrededor de una cultura de masas. La cultura de masas no conforma un pueblo de forma histórica mediante tradiciones transmitidas a través de múltiples generaciones y que permite que lo que suceda tenga sentido en un devenir histórico y con referencia al bien común. Se trata más bien de una especie de anti-cultura que impide la posibilidad de una voluntad holística favoreciendo así a pequeños fragmentos desconectados unos con los otros. La cultura de masas congrega individuos alrededor de algunos pocos patrones homogéneos y fragmentados de identificación y cuya agrupación les permite participar en el único espacio social permitido bajo la globalización: el mercado.

No obstante, las contradicciones propias de un sistema cada vez más excluyente de las grandes mayorías alcanzan el nivel de crisis, lo cual permite que las mayorías excluidas critiquen al sistema dominante. Veremos entonces qué ocurre en la Venezuela de finales del siglo XX.

\section{Venezuela a finales del siglo $\mathrm{XX}$}

Con el proceso de homogeneización mundial de la globalización, las naciones devienen en meros mercados. En consecuencia, los seres humanos se conciben como compradores y proveedores. La relación con los otros se entiende únicamente basada en el intercambio en el que ambas partes procuran beneficiarse individualmente de acuerdo a sus preferencias particulares. Los Estados reducen su presencia para convertirse exclusivamente en organizaciones reguladoras del mercado.

Al concebirse la interrelación con los otros en términos de mercado no es de extrañar que emerja una cultura de masas identificada exclusivamente en términos de patrones de consumo. Al perder el mundo la trascendencia de la tradición cultural, la producción se reduce a productos desechables y perecederos inmanentes al proceso de consumo. Productos fugaces consumidos masivamente por los consumidores.

Lejos quedan los tiempos de las imperecederas obras culturales y del cultivo de la memoria de esas obras en la sociedad de generación en generación y que muestran la raíz cultural que les subyace y que las plena de sentido. El sentido de lo cultural no va más allá de su valor de mercado y por ello es únicamente concebido en términos de máximas utilidades por el mínimo costo. 
El artesano que sopesaba cuidadosamente la confluencia de la materia, la forma y la finalidad para que su obra fuese expresión plena de su cultura, el agricultor que apreciaba meticulosamente la reunión de la semilla, el agua y el tiempo en surcos trazados cuidadosamente en la respetada, amada, temida y alabada tierra y que además velaba sus brotes para recibir agradecidamente los dones en la cosecha, ellos -el artesano y el agricultorceden su lugar en el mundo al ingeniero. El ingeniero que todo lo encuadra en los criterios "minimax" y "maximin" de la optimización de procesos.

Desde el gobierno de Luis Herrera Campins, luego en el de Jaime Lusinchi y con mayor fuerza en el segundo gobierno de Carlos Andrés Pérez comenzaron a implantarse en Venezuela proyectos de nación con una creciente orientación neoliberal que fueron insertando al país en la globalización. En el año 1989, cuando Pérez asume su segunda presidencia, se intenta la implantación de un programa de gobierno que terminase de insertar, rápidamente, el neoliberalismo. En otras palabras, que convirtiese apresuradamente a la nación en una sociedad de mercado.

El 27 y 28 de Febrero del año 1989, masas de excluidos en distintas ciudades del país salieron espontáneamente a las calles a protestar. Las masas de los que habían sido marginados de la economía, de la política y de la cultura salieron a las calles a destruir comercios precisamente en el momento cúspide en que la nación estaba siendo enajenada de su posibilidad de ser pueblo. Salieron en el momento en que parecía inminente que la nación sería devorada por la globalización para convertirse en una suerte de forma neo- colonial fundada en el mercado y muy parecida, metafóricamente, a un centro comercial.

Las acciones de saqueo y destrucción de comercios muestran de por sí la dualidad de la acción. Por una parte el saqueo del comercio parece proferir el grito de "¡Inclúyannos! en la sociedad de mercado". Por otra, la destrucción de los comercios parece exigir una sociedad profundamente distinta pero en la cual no se logra definir con claridad las alternativas de sociedad que pudieran impulsar los reclamos de esas masas excluidas.

Luego del 27 y 28 de Febrero el gobierno de Carlos Andrés Pérez mantuvo la misma política globalizadora -con algunos cambios entre sus funcionarios de alto nivel- aplacando las masas de los excluidos con una represión cruenta e intensa y programas de subsidios directos que se definieron para atender la coyuntura político-social como una variable que se había salido de control por un período breve de tiempo. Al menos, esa fue la evaluación más difundida de los eventos de Febrero 1989.

En 1992 ocurren dos intentos militares de golpe de Estado. Aunque los dirigentes de tales intentonas fueron apresados, poco a poco su discurso empieza transmitirse por todo el país. Así, se empieza a escuchar un discurso nacionalista que procuraba rescatar ideas de Simón Bolívar, Simón Rodríguez y Ezequiel Zamora. Algunas ideas de inclusión, libertad e independencia resuenan en armonía, a veces disonante y siempre asincopada, con un discurso que rescata la nación.

Pérez sale del gobierno por acusaciones de malversación de fondos y peculado. En las elecciones siguientes sale 
victorioso el Dr. Rafael Caldera, quien, si bien es uno de los personajes más emblemáticos de la democracia representativa de la Venezuela del Siglo XX, había roto con el partido COPEI, que él había fundado, y en un discurso en el Congreso Nacional a propósito del golpe de Estado del 4 de Febrero mostraba situaciones que justificaban tal acción. No obstante, las políticas globalizadoras se mantuvieron durante ese periodo gubernamental adelantando políticas de flexibilización del sector laboral y protección del capital financiero que son características propias del proceso de dolarización de los países periféricos al desarrollo.

Posteriormente, en diciembre del año 1998, se enfrentan electoralmente el líder de la intentona golpista: Teniente Coronel Hugo Chávez Frías y el Economista Henrique Salas Römer. Es interesante recordar las características de estos personajes porque en ella parece reflejarse profundamente la tensión entre nación y mercado de la que hemos venido hablando. Chávez, con un discurso de inclusión dominado por la justicia social y la necesidad de revertir procesos de enajenación de la nación venezolana. Su principal planteamiento político-electoral se centró en la convocatoria a una constituyente que permitiera replantear el concepto de nación, democracia y ciudadanía ante el agotamiento y pérdida de legitimidad del sistema dominante en Venezuela. Salas Römer, representante emblemático de las formas de vinculación político-industrial que se dieron durante el período comprendido entre 1958 y 1998 en el cual procesos de exclusión social y político hicieron inviable un sistema social, económico y político que nunca fue objeto de debate político en la sociedad venezolana. Y de la contienda salió victorioso Chávez... Es que el malestar de la globalización parece aliviarse un poco con el discurso neo-bolivariano que retoma ideas dispersas en las que resuenan nación y pueblo.

El 2 de Febrero de 1999 el nuevo presidente asume la jefatura del Estado venezolano y promueve un referéndum a realizarse el 25 de Abril del mismo año para consultar la aceptación popular de la refundación de la república en una nueva Constitución Nacional. Gana la opción de la refundación, se elige una Asamblea Nacional Constituyente, se redacta la nueva Constitución, se presenta a la nación el 20 de Noviembre y finalmente es aprobada por Referéndum el 16 de Diciembre de 1999.

\section{Venezuela y la Constitución de 1999}

En la Constitución de la República Bolivariana de Venezuela de 1999 se busca la conformación de un Estado democrático y social de Derecho y de Justicia que a través de la promoción de la participación ciudadana y el desarrollo y defensa de la persona, fundamentados en la educación y el trabajo, refunde la República para establecer una sociedad democrática, participativa y protagónica, multiétnica y pluricultural.

El papel del desarrollo es redefinido en la nueva Constitución y se plantean como ejes para el bienestar común la articulación de la educación y el trabajo en un marco de diversidad cultural y étnica arraigada en procesos de participación popular. La posibilidad de centrar en la 
educación y el trabajo el bienestar de la república parece ir más allá del desarrollo de competencias individuales para engranarse en el aparato productivo.

Empezaremos por acercarnos a entender la concepción de "trabajo" que se puede inferir desde una interpretación de la Constitución de 1999. El trabajo es entendido como una ocupación productiva que le permita al trabajador vivir con dignidad para "cubrir para sí y su familia las necesidades básicas materiales, sociales e intelectuales" (Artículo 91). Para entender lo que se entiende por las "necesidades" debemos ver algunos de los otros artículos de la Constitución. Empezaremos por las "necesidades intelectuales", las cuales están ligadas a la educación y que como recordamos es el otro proceso fundamental para el desarrollo de la persona.

"La educación es un derecho humano y un deber social fundamental, es democrática, gratuita y obligatoria". Como se deriva de lo anterior, el Estado tiene el deber de asumirla como servicio público y con respeto a todas las corrientes del pensamiento. La educación debe procurar el desarrollo del "potencial creativo de cada ser humano y el pleno ejercicio de su personalidad en una sociedad democrática basada en la valoración ética del trabajo y en la participación activa, consciente y solidaria en los procesos de transformación social, consustanciados con los valores de la identidad nacional y con una visión latinoamericana y universal..." (Artículo 102).

Podemos ver que la educación procura desarrollar el potencial creativo del ser humano al vincularse al trabajo pues este se considera un espacio adecuado para la creación del ser humano. Ahora bien, como podemos ver en el Artículo 102 arriba citado, la educación no sólo debe inculcar la valoración ética del trabajo y desplegar el potencial creativo en los ciudadanos, sino que debe también inculcar la valoración por, y desplegarse en, la participación ciudadana para la transformación social. Participación que debe estar impregnada por "los valores de identidad nacional, y una visión latinoamericana y universal". A lo anterior se le añade que la educación es también "un instrumento del conocimiento científico, humanístico y tecnológico que debe estar al servicio de la sociedad".

Puede entenderse que subyace en la Constitución un ideal de ciudadano en el cual, además del reconocimiento de una libertad para desarrollarse como persona de acuerdo a sus preferencias y decisiones particulares, debe asimismo desplegar su potencial creativo a través de la participación ciudadana en beneficio de la sociedad. De este modo podemos discernir que a la Constitución la anima un ideal de ciudadano que no es una partícula aislada sino que está constituido por los valores de identidad nacional, latinoamericana y universal. Lo anterior parece apuntar a que las "necesidades" a satisfacer en el ciudadano no se agotan en lo individual. Al contrario, esas "necesidades" implican deberes del ciudadano para con la sociedad.

Por ello, en el Artículo 100, la Constitución afirma que las culturas populares son constitutivas de la pluriculturalidad venezolana y que en consecuencia deben gozar de atención especial. Por lo tanto, el espíritu que subyace a la Constitución es uno en el cual el ser venezola- 
no, la venezolanidad, no es algo fijo y estático sino que debe ser fomentado y promovido. Así el Artículo 99 establece que "los valores de la cultura constituyen un bien irrenunciable del pueblo venezolano y un derecho fundamental que el Estado fomentará y garantizará..." Es como si lo venezolano deba nutrirse constantemente $y$ en consecuencia deban brindarse "incentivos y estímulos para las personas, instituciones y comunidades que promuevan, apoyen, desarrollen o financien planes, programas y actividades culturales en el país..." (Artículo 100). Es como si lo venezolano deba estar recreándose constantemente.

De lo anterior se deduce que "lo venezolano" no es sólo el territorio que se corresponde con la Capitanía General de Venezuela para el 19 de Abril de 1810 (Artículo 10), sino que está más relacionado con el proceso cultural de creación y recreación de la identidad venezolana. Puede entenderse además que siendo el proceso de creación y re-creación cultural un proceso dinámico que cuenta con variados afluentes y que es además un proceso de libre creación (Artículo 98), no sea apropiado entender a la cultura venezolana como única sino como múltiple. La venezolanidad trasciende y brinda unidad a múltiples culturas venezolanas. La venezolanidad es también multiétnica porque trasciende y brinda unidad a las diversas etnias que confluyeron y se mezclaron cultural y biológicamente en la formación del pueblo venezolano. Lo anterior debe entenderse, asimismo, como una cultura venezolana que está inmersa en una visión que la trasciende a ella misma para ir hacia lo latinoamericano y hacia lo universal.
Visto así, la educación es el proceso fundamental de transmisión y desarrollo de la cultura venezolana. El trabajo es el proceso de creación y recreación de esa cultura. La educación y el trabajo consustancian, y son consustanciados por, el pueblo venezolano. El ciudadano venezolano, si bien es libre de escoger su trabajo y su creación cultural, se debe a su cultura porque está primariamente constituido por ella. El desarrollo y la defensa de la persona, según la Constitución, procuran el desarrollo de las capacidades de creación y recreación del ser venezolano en un contexto dinámico multicultural y multiétnico, latinoamericano y universal.

Dado lo anterior podemos volcarnos sobre el tema de la "participación ciudadana". La educación que transmite y desarrolla la venezolanidad hace énfasis en lo siguiente: "...El Estado, con la participación de las familias y la sociedad, promoverá el proceso de educación ciudadana, de acuerdo con los principios contenidos en esta Constitución y en la ley" (Art. 102). Así vemos que la educación tiene un especial énfasis en la formación del ciudadano y que en ello debe participar tanto el Estado como la familia y la sociedad. Si seguimos indagando al respecto nos encontramos que en el Artículo 62 se establece que "todos los ciudadanos y ciudadanas tienen el derecho de participar libremente en los asuntos públicos, directamente o por medio de sus representantes elegidos o elegidas" y en el Artículo 132 se establece que "toda persona tiene el deber de cumplir sus responsabilidades sociales y participar solidariamente en la vida política, civil y comunitaria del país, promoviendo y defendiendo los derechos humanos como fun- 
damento de la convivencia democrática y de la paz social".

De tal manera que la educación tiene como referencia a la participación ciudadana. Educación que como puede verse trasciende el plano formal de la escuela, para desplegarse en las interrelaciones sociales diversas del ciudadano. Participación que se concibe como un derecho que se puede ejercer particularmente o a través de un representante. Participación que es un deber de todo ciudadano para así cumplir con sus responsabilidades y participar solidariamente en procura de fundamentar la convivencia democrática. Puede entenderse de lo anterior, que la democracia no es sólo vista como el ejercicio del sufragio, sino que la democracia exige tanto el sufragio democrático como la participación activa de los ciudadanos en la vida socio-política de la república. Por ello es una democracia participativa y protagónica. El ciudadano no es sólo un receptor que emite su opinión en el sufragio sino que debe participar, ser protagonista, de lo público. La participación ciudadana se encuentra en plena concordancia con la idea de cultura venezolana que hemos presentado puesto que a través de dicha participación podemos entrar en el proceso de creación y re-creación de lo venezolano.

Es en este sentido que el Artículo 62 termina señalando que "la participación del pueblo en la formación, ejecución y control de la gestión pública es el medio necesario para lograr el protagonismo que garantice su completo desarrollo, tanto individual como colectivo. Es obligación del Estado, y deber de la sociedad, facilitar la generación de las condiciones más favorables para su práctica".
Claro está que para posibilitar el espacio de participación ciudadana, trabajo y educación (todos conformados y conformantes de la venezolanidad) se necesita de un nivel básico de Justicia (social y penal) para todos los ciudadanos. En este sentido, el Estado debe asegurar derechos tales como: la vida, la libertad personal, respeto a la integridad física, psíquica y moral de la persona, inviolabilidad del hogar, inviolabilidad de la comunicación, justicia criminal y libertad de transito y asociación. También debe brindarse el derecho a tener nombre propio, a tener acceso al Estado, a dedicarse a la actividad económica de su preferencia, a ser informado de forma veraz y oportuna y a satisfacer necesidades básicas como vivienda y salud. Por último, el ciudadano tiene derecho a la libre expresión del pensamiento, a profesar y manifestar su religión, al respeto del honor propio, a su privacidad y a manifestar su conciencia libremente.

Asimismo, es necesario que el ciudadano cumpla con ciertos deberes y el Estado debe ser garante de este cumplimiento. Algunos de estos deberes son el acatamiento de las leyes, el pago de impuestos y la prestación de servicio civil o militar. Finalmente recordemos que el trabajo, la educación y la participación ciudadana son derechos y deberes de todos los ciudadanos.

En resumen, puede entenderse que el ideal de ciudadano en la Constitución de la República Bolivariana de Venezuela procura principalmente el desarrollo y la defensa de la persona. Para ello, en primer lugar, el Estado venezolano pretende brindar un mínimo de derechos básicos. Derechos que le permitirán al 
ciudadano vivir dignamente para poder participar de la sociedad. El desarrollo de la persona es realizado a través del trabajo y la educación. Ambos construyen y son construidos por la cultura nacional. De este modo, el trabajo y la educación crean, recrean, desarrollan y transmiten la cultura venezolana vista en su contexto latinoamericano y universal. En consecuencia, todo ciudadano tiene el derecho y el deber de participar en la formación, ejecución y control de lo público. De modo que la participación ciudadana es un modo de crear, recrear, desarrollar y transmitir la cultura venezolana. Cultura que no se entiende como única, sino como trascendente a la confluencia de las múltiples culturas y etnias conformantes de la venezolanidad.

De lo anterior puede deducirse claramente que el desarrollo al que debe apuntalar una ODR en el siglo XXI no debe y no puede estar limitado al crecimiento económico. No puede ser un desarrollo local puesto que ello iría en contra del espíritu de refundación nacional que subyace a la Constitución. La lectura que debemos realizar del Artículo 128 según el cual "el Estado desarrollará una política de ordenación del territorio atendiendo a las realidades ecológicas, geográficas, poblacionales, sociales, culturales, económicas, políticas, de acuerdo con las premisas del desarrollo sustentable, que incluya la información, consulta y participación ciudadana...", no puede ser entendida de modo tal que todos los factores deban revisarse en función del crecimiento económico. Más bien, este desarrollo sustentable debe revisarse en función del desarrollo de la persona a través de la educación y el trabajo como ele- mentos fundamentales de la conformación cultural en la que se identifica la persona misma y que nos conforma como pueblo venezolano.

De este modo puede verse que la visión de desarrollo tecno-económico no es celebrada por la Constitución de 1999 y que, en contraste, se procura una República fundamentada en la persona (conformada en y conformante de su cultura nacional) en una sociedad democrática, participativa y protagónica. Queda lejos la visión hegemónica que dividía las sociedades homogéneamente en desarrolladas y subdesarrolladas. En la próxima sección esbozaremos una teoría alternativa de desarrollo que posibilite celebrar las nociones que subyacen a la Constitución de 1999 y que esté fundamentada en lo endógeno y en la sustentabilidad.

\section{Hacia un desarrollo endógeno sustentable}

La noción de desarrollo endógeno sustentable parte de la identificación, apropiación y comprensión de un punto de inflexión histórico del concepto de desarrollo. Punto que denota el cambio paradigmático y la superación de la dimensión positivista del desarrollo, la cual puede resumirse en las siguientes características:

a. El desarrollo es un proceso lineal y predecible.

b. Está condicionado por la imposición de valores asociados a un agente que desarrolla y otro que se asume es el objeto del desarrollo.

c. Los resultados del desarrollo están condicionados y limitados a la relación causa-efecto. 
El poder superar esta forma de entender el proceso de desarrollo nos obliga a concebir un proceso de aprendizaje y participación del ciudadano que contrasta con las formas usualmente asociadas a las técnicas de planificación y desarrollo propias de los procesos centrados en el mejoramiento del desempeño económico medido a través de los agregados macroeconómicos.

De este modo, se trata de la búsqueda de mecanismos que permitan descentralizar el desarrollo con respecto a lo económico y formularlo en torno al hombre. Se postula entonces, una concepción antropocéntrica del desarrollo, y en consecuencia, se requiere atender el modo como se constituye histórica y culturalmente el sujeto del desarrollo, en nuestro caso, el venezolano de comienzos del siglo XXI.

Desarrollar es des-arrollar, es decir, permitir que lo que está oculto sea desplegado. Pero, ¿qué es lo que se despliega cuando se trata del hombre? Si reconocemos al hombre como una construcción histórico-cultural, entonces lo que se despliega no es un objeto previamente determinado ni las condiciones o potencialidades de una naturaleza específica del hombre. En realidad, lo que se despliega, lo que se desarrolla, son las posibilidades del quehacer social. Nótese que en la actualidad el quehacer social está limitado a la actividad económica relegando así, otros aspectos vitales para la sociedad. Superar la auto-legitimación de lo económico constituye entonces el primer paso para establecer una relación libre con la economía y permitir el despliegue de posibilidades, es decir, el desarrollo de la sociedad desde sus propias potencialidades y vocaciones.
Ahora bien, ¿Qué significa una relación libre con la economía? ¿Por qué es importante una relación libre con la economía?

Una relación libre con la economía implica la tarea de entender lo económico como un resultado de complejas relaciones que se dan en la sociedad y no entenderla como una manifestación independiente y dominante del devenir de la sociedad. La necesidad de establecer esta relación libre es incluso más urgente en sociedades como la venezolana, en la que, sus patrones sociales, económicos y culturales son profundamente dependientes de otras sociedades, culturas y economías.

De este modo, el problema del desarrollo definido y asimilado culturalmente como el conjunto de pasos para alcanzar los criterios de actuación económica, no constituye la premisa fundamental sobre la cual se debe concebir la aproximación al desarrollo y su planificación. Es precisamente lo contrario, se trata de concebir al desarrollo como una pregunta que interroga a la sociedad desde los aspectos más elementales de su funcionamiento hasta su núcleo de identidad colectiva.

Esta problematización debe tener su origen desde el interior de la misma sociedad e involucrar a todos los actores, interesados y afectados, sobre una determinada forma de definir y alcanzar lo que se considera bueno para esa sociedad. La condición interna hace referencia a la necesidad de poder descubrir y comprender aquello que hace posible o imposible, la definición de lo que es común para todos a partir del despliegue histórico de cómo se ha llegado a ser y cuáles son las posibilidades que se revelan y aquellas 
que se ocultan. Estas condiciones constituyen un cierto modo de ser cultural, el cual permitirá a la sociedad poder proyectar los espacios de intervención para realizar lo que se propone como expectativas comunes y en base a lo que puede llegar a ser, sin tener que apelar a la imitación de las formas culturales dominantes en otras sociedades y que se imponen como buenas para todos, tal como lo planteaba el modelo desarrollista de mediados del siglo XX.

Esta construcción colectiva es lo que denominaremos quehacer social. Con mayor precisión, entendemos por quehacer social la actividad sistemática a través de la cual el hombre construye significados y hace mundo en reunión con otros. En este sentido, el quehacer social está fundado en la búsqueda de la vida digna y la realización del bienestar público.

La búsqueda de la vida digna supone que existe un conjunto de necesidades básicas que necesitan estar atendidas en el proceso de inclusión de todos en ese quehacer social y la construcción de una identidad colectiva que apuntale una ética que se funde sobre los valores identificados por la propia sociedad como buenos. Estos dos últimos aspectos, la búsqueda de la vida digna y la construcción de una identidad colectiva, son condicionantes del modo como se entiende el quehacer social y la generación de bien-estar colectivo.

A nuestro entender, el concepto fundamental de desarrollo es entonces formulado en los siguientes términos:

\section{DESARROLLO: DESPLIEGUE DEL QUEHACER SOCIAL EN ARMONÍA CON SU ENTORNO.}

Por "entorno" entendemos al espacio de relaciones espaciales, materiales, culturales, políticas y económicas en donde el hombre construye sentido colectivamente, es decir, donde el hombre hace mundo.

En este contexto, un proceso de desarrollo orientado al despliegue de las potencialidades del hombre en su entorno, es decir, del quehacer social exige:

a. La decisión local sobre las opciones de desarrollo.

b. El control local sobre los procesos de desarrollo.

c. La retención de los beneficios del desarrollo en la misma comunidad.

Esta forma de entender el desarrollo la denominaremos desarrollo endógeno sustentable. Las implicaciones de estas tres condiciones básicas son de distinta envergadura e involucran a los actores de la sociedad de forma distinta dependiendo de sus fortalezas y responsabilidades. Una primera aproximación revela un conjunto de elementos mínimos para cada condición:

1. La Decisión Local sobre las Opciones de Desarrollo. Parte del despliegue de las potencialidades del hombre tiene que ver con aquello que se busca desplegar. Es condición del bien-estar humano la posibilidad de construir el mundo en el cual habita. Esta construcción implica decidir el qué hacer y cómo hacerlo. Para ello es necesario que el hombre en comunidad pueda:

1.1. Reconocerse como sujeto $y$ objeto del desarrollo. Colectivamente se presentan, discuten y deciden sobre las actividades orientadas a alcanzar las opciones de desarrollo y la incidencia positiva o negativa, de esas opciones de desa- 
rrollo, positiva o negativa, en la comunidad y sus miembros.

1.2. Creary desplegar las opciones de desarrollo en la comunidad. Apropiarse de su quehacer social. Se trata de identificar las mejores prácticas y quienes la realizan en función de hacer suyo el quehacer social.

1.3. Comparar las opciones de desarrollo de la comunidad con actividades similares o complementarias que ocurran en los ámbitos regional, nacional e internacional.

1.4. Evaluar el impacto de las opciones de desarrollo para que el quehacer social sea cónsono con la cultura de la comunidad. A partir de los criterios de pertinencia social, ambiental, cultural y económica de las opciones desde una visión integral de la comunidad.

1.5. Seleccionar las opciones de desarrollo adecuadas.

\section{El Control Local sobre el Desa-} rrollo. Supone la articulación de los medios apropiados para alcanzar las opciones escogidas en armonía con el quehacer social de la comunidad. Se espera que la comunidad pueda:

2.1. Identificar los medios (procesos, herramientas, capital social) con los cuales cuenta para alcanzar las opciones de desarrollo escogidas.

2.2. Identificar los mecanismos de acceso y asimilación para aquellos medios con los cuales no se cuenta en la comunidad.

2.3. Articular los medios en función de garantizar la continuidad del quehacer social.

2.4. Ejecutar la opción.

2.5. Hacer seguimiento de los planes.

\section{La Retención de los Benefi-} cios del Desarrollo en la Comunidad. Debe entenderse que los beneficios del desarrollo no se limitan a los objetos de intercambio en el mercado de bienes materiales, se pretende que algunos de los beneficios de las opciones se reproduzcan en ventajas para seguir desplegando las actividades consideradas claves para el sostenimiento y mejoramiento de las opciones de desarrollo de la comunidad. Así, la comunidad debe ser capaz de:

3.1. Evaluar los resultados de las opciones de desarrollo ejecutada en los distintos ámbitos del quehacer social.

3.2. Determinar los requerimientos necesarios para la continuidad de las opciones de desarrollo y la mejoría en su ejecución.

3.3. Identificar los beneficios directos e indirectos de la actividad en el quehacer social de la comunidad.

3.4. Reforzar aquellas otras actividades que promueven la opción de desarrollo como viable, deseable y sustentable en la comunidad.

\section{El sentido político del Desarrollo Endógeno en el presente}

En la identificación de las tareas que son necesarias para garantizar la condición endógena del desarrollo, se hace evidente la importancia de la dinámica entre ciudadanos, territorio y Estado que apunta hacia una dirección opuesta a las formas de relación entre estos tres componentes que se dan en el marco del desarrollo económico, estos son considerados solamente desde su contribución a 
la actividad económica dentro de un orden regido por el mercado.

En la propuesta de un desarrollo generado desde dentro se vuelve a plantear la separación entre un adentro y un afuera que fue abolido por los procesos de integración multinacional guiados por la apertura de mercados y la ruptura de las barreras comerciales nacionales. En este sentido, el desarrollo endógeno inicia un tránsito de carácter nacionalista 0 , mejor dicho, una propuesta de ejercicio soberano sobre el territorio que plantea, no sólo interrogantes sobre las formas de concebir ese ejercicio, sino incluso, pone sobre la mesa de discusión la pertinencia de la soberanía en un mundo cada vez más entendido como un enorme mercado global con rezagados en los países que aún propician accesos diferenciados y selectivos al mercado.

Siendo este el caso, el desarrollo endógeno sustentable aparece no sólo como una respuesta a la recurrente pregunta acerca del modo de alcanzar el desarrollo. Se propone más bien como un concepto auxiliar para volverse a plantear preguntas fundamentales vinculadas al modo como los miembros de una sociedad hacen uso de sus potencialidades y vocaciones en afinidad con lo acordado en los espacios de concertación que se construyen con la participación del Estado. Este último, entendido como el instrumento que la sociedad constituye para garantizar el reconocimiento de los otros por parte de todos.

La vinculación entre ciudadanía, territorio y Estado es entonces replanteada. No se trata de una vinculación abstracta fundada en el mercado, sino de una asociada con las peculiaridades de un determinado territorio y la configuración que de él se hace a partir de los modos como los ciudadanos asumen su vida, su quehacer social, en ese territorio; con el Estado como garante de los espacios de concertación necesarios para el proceso de desarrollo.

La vinculación entre ciudadanía, territorio y Estado en el desarrollo endógeno sustentable se puede concebir como constituida por distintas capas que se definen en función de un modelo básico de sociedad. Estas capas las denominaremos como: capa productiva derivada del quehacer relacionado con la generación de bienes materiales; capa innovadora-educativa la derivada del quehacer propio de la generación de conocimiento y la transmisión de saberes; capa social derivada del quehacer relacionado con la dependencia entre los miembros de la sociedad; y capa institucional derivada de la necesaria sistematización de algunas relaciones entre los miembros de la sociedad.

Todas estas capas están definidas como redes en las cuales se intercambian permanentemente información, necesidades, problemas, propuestas y soluciones. Alimentando todo este circuito de redes se va develando y desplegando la cultura que trasciende a las distintas capas y que permite el desarrollo. La cultura se atisba en las distintas tareas identificadas para el desarrollo endógeno como aquello que impulsa y posibilita los procesos de apropiación de beneficios, tecnologías, avances, amenazas y fortalezas con los cuales la sociedad asume como propio la constitución de su porvenir.

El aspecto más resaltante del desarrollo endógeno sustentable es precisamente su constitución como condición 
de posibilidad para impulsar procesos de transición hacia una sociedad orientada por la comprensión de su propio quehacer; la puesta en cuestionamiento del modo cómo ha alcanzado la situación en la cual se encuentra actualmente; y las posibilidades que esa situación comporta para el florecimiento de las capacidades humanas de sus miembros.

Es precisamente desde la revisión de los fundamentos sobre los cuales una sociedad se intenta re-pensar a sí misma, que la endogeneidad se convierte en motor de nuevos procesos de definición del bienestar para la sociedad. En este sentido, trasciende a la dicotomía: "globalización" vs. "localismo" y se busca la definición de un ámbito de cómo pensar una sociedad justa desde la reconstrucción histórica de sus propias raíces y el reconocimiento de su quehacer social y cuanto de ello se corresponde con el espacio geográfico donde ocurre ese quehacer.

La reconstrucción histórica de la sociedad, en el caso particular de sociedades periféricas o marginales al discurso modernizador dominante hasta el presente, implica una apropiación de la cultura que se formula desde las propias preguntas constitutivas de la identidad colectiva. En este sentido, es precisamente la promoción y existencia de procesos de aprendizaje e incremento de las capacidades críticas de los miembros de la sociedad a través de los cuales se va destilando el proceso de reconocimiento de humanidad de todos y de la posibilidad de establecer diferencias que no impliquen procesos de exclusión social, política y económica.

\section{Sentido de una ODR a principios del siglo XXI}

Dado todo lo anterior se entiende que una ODR debe definirse en términos de una concepción de desarrollo que supere la visión tecno-economicista y los patrones culturales de dependencia heredados del industrialismo y posibilite la transformación hacia formas organizacionales que superen los complejos mecanismos clientelares de distribución de los recursos del Estado. Se trataría así de una organización dirigida a la promoción del despliegue del quehacer social mediante procesos de apropiación de las comunidades con su historia y su identidad en la toma de decisiones locales sobre el tipo de quehacer que revele más propiamente su cultura, en el control de esa realización y en la retención de los beneficios que se generen. Todo ello en función de procurar una ciudadanía que posibilite la refundación de la República en términos de una sociedad democrática participativa y protagónica, pluricultural y multiétnica en la que se desarrolle la persona a través de la educación y el trabajo.

La ODR deberá promover mecanismos de rescate y apoderamiento de los saberes que la comunidad considere más propios y que revelan su modo de hacer sentido de su quehacer social, lo cual no implica cerrarse a otros saberes. Al contrario, se trata de asumir que cualquier otro saber (e.g. el conocimiento científico) será llamado desde la problemática propia de la cultura y no como un saber apodíctico que revela una verdad incuestionable. Es importante también destacar que este saber local no debe 
concebirse de manera tal que pueda cerrarse en sí mismo, sino que él debe entenderse como uno que es, en una cultura que tiene dimensiones trascendentales hacia lo nacional y lo universal. Por ejemplo, en el caso de una ODR andina venezolana, ésta debe procurar generar y compilar conocimientos que potencie las capacidades de despliegue de la cultura andina venezolana dentro de un marco global más amplio que la sitúe como un espacio de la cultura venezolana, de la cultura andina sudamericana, de la cultura latinoamericana y de la cultura universal.

La promoción del saber local exige la dimensión participativa y protagónica del ciudadano en el proceso de planificación que debe posibilitar y promover la participación y el protagonismo tanto de los niveles estadales y municipales del Estado como de las comunidades directamente. Se trata de una participación que no debe entenderse en los términos de mercado. Es decir, la participación no debe ser en términos de influenciar las decisiones de acuerdo a mis intereses individuales. La participación debe buscar la realización de la sociedad pluricultural y multiétnica a través del despliegue de la cultura local -o las culturas locales- propia de la región.

Finalmente, la ODR debe procurar redefinir la relación entre Estado y sociedad de manera tal que el Estado cumpla su función de "encarnación" de lo público. Ello debe hacerlo por dos razones: una teórica y otra histórica. La razón teórica responde a la redefinición del concepto de desarrollo que estamos manejando y que supone que el Estado no debe entenderse exclusivamente como el árbitro que regula el mercado sino que debe buscar la promoción de lo endógeno. Por otra parte, la razón histórica a la que queremos llamar la atención responde a que debido al fracaso del proyecto modernizador venezolano se desvirtuaron las relaciones entre el Estado y la sociedad y se crearon estructuras clientelistas que impidieron que el primero hiciera una justa distribución de los bienes públicos, es necesario que desde la ODR se procure la transformación del Estado en función de lograr fortalecer las relaciones entre uno y otro y así posibilitar que el Estado realice las funciones que en justicia le corresponden.

Si las ODR han vuelto al discurso político no ha sido por su pertinencia como organizaciones que pueden potenciar el desarrollo tecno-económico sino como agentes que pueden promover el despliegue de la cultura regional en función de lo nacional y de lo universal. Desarrollo que no debe entenderse como la promoción de productos folclóricos de compra y venta, sino como el proceso de creación y recreación de lo público, del bien común, de lo que nos identifica como comunidad y como pueblo. Se trata de un ejercicio ciudadano en función de re-crearnos como venezolanos desde la recreación de nuestra cultura regional para que desde allí participemos en la cultura universal superando las antípodas del desarrollo industrial y la globalización.

\section{A modo de conclusión}

La aparición en el discurso actual del concepto Desarrollo Endógeno Sustentable puede significar el surgimiento de nuevos espacios de discurso y cons- 
trucción social de la realidad que apunten hacía la promoción de formas alternas de entender el desempeño de la sociedad occidental, y en general del mundo, desde una perspectiva más incluyente a partir no sólo del reconocimiento de la autonomía y la libertad sino de, quizás, elementos más modestos pero más evidentes como lo son la dependencia entre los hombres y el rápido agotamiento de los recursos que le permiten hacer hogar en el planeta tierra.

Esto supone que la aparición de formas institucionales destinadas al Desarrollo Endógeno Sustentable se encuentran destinadas a la reconstrucción de formas sociales, culturales, políticas y económicas que superen las formas históricas derivadas del Estado liberal y que han sido puestas al servicio del proceso de homogeneización y globalización económica como única fuente de legitimación. Las implicaciones para el ordenamiento de un Estado más eficiente pero más comprometido en su misión de propiciar el bienestar para todos y la reconstitución del entramado ciudadano e institucional que permita una participación crítica y, en esa misma medida, co-responsable constituyen sólo algunos de los elementos que serán necesarios atender para trascender del usual discurso tecnológico que haciendo uso de palabras de moda sigue imponiendo la racionalidad tecnológica y totalitaria de la eficiencia y productividad, incluso por encima del hombre.

Esta aproximación conceptual abre el proceso de debate tan necesario para poder definir desde dentro de la sociedad venezolana lo que entendemos por el despliegue de las posibilidades del quehacer social en armonía con el entorno.

\section{Referencias Bibliográficas}

\section{Baptista, Asdrúbal (1997). Bases cuantitati-} vas de la economía venezolana. Fundación Polar. Caracas.

Baptista, Asdrúbal (2004). El relevo del capitalismo rentístico. Hacia un nuevo balance de poder. Fundación Polar. Caracas.

Cárdenas, Nersa (2002). El desarrollo local, su conceptualización y procesos. Provincia No. 8. Enero-Junio 2002. Pp. 53-76. Mérida.

Clarac de Briceño, Jacqueline (1976). La cultura campesina en Los Andes venezolanos. Consejo de Desarrollo Científico y Humanístico. Mérida.

Contreras, José J. y Ochoa, Alejandro E. (2000). "Una exégesis crítica al sentido del desarrollo sostenible de las Américas en el marco de la globalización". Cuadernos del Cendes. Año 17. No. 45. Segunda Época. Septiembre-Diciembre. Pp. 1-22. Caracas.

Fuenmayor, Ramsés (2000). Sentido y Sinsentido del Desarrollo de un País. Consejo de Publicaciones-Consejo de Estudios de Postgrado. Universidad de Los Andes. Mérida.

Fuenmayor, Ramsés (2001). "Venezuela: su enfermedad y su crisis actual". En Libro Homenaje a Humberto J. La Roche Rincón. Colección Libros Homenaje - $N^{0} 3$. Tribunal Supremo de Justicia. Caracas.

Fuenmayor, R. y López-Garay, H. (1991). "The Scene for Interpretive Systemology". Systems Practice. Vol. 4. No. 5; Pp. 401-418. Nueva York.

López Garay, Hernán (1991). An InterpretiveSystemic Study of the Regional Planning Corporation of Los Andes in Venezuela. Systems Practice. Vol. 4. No. 5. Nueva York. 
Meadows, D. y otros (1975). Los límites del crecimiento. Fondo de Cultura Económica, $2^{\mathrm{da}}$ reimpresión, Trad. de Ma. Soledad Loaeza, México.

Mommer, Bernard (2001). "La Encrucijada de la Política Petrolera Venezolana. Re- vista BCV. Vol XV. $\mathrm{N}^{0} 1$. Banco Central de Venezuela. Pp. 155-161. Caracas.

World Commission on Environment and Development (1987). Our Common Future. Oxford University Press. Oxford. 